\title{
Toward a better understanding of the effects of cement treatment on microstructural and hydraulic properties of compacted soils
}

\author{
Harifidy Ranaivomanana ${ }^{1,{ }^{*}}$, and Andry Razakamanantsoa ${ }^{2}$ \\ ${ }^{1}$ Institut de Recherche en Génie Civil et Mécanique (GeM), UMR-CNRS 6183, Université de Nantes \\ (IUT de Saint-Nazaire), 58, Rue Michel Ange, 44606, Saint-Nazaire, France \\ 2 IFSTTAR, Institut Français des Sciences et des Technologies des Transports, de l'Aménagement et \\ des Réseaux, CS 4 Route de Bouaye, 44344, Bouguenais, Cedex France
}

\begin{abstract}
This study deals with the problem of the experimental characterization of cement-treated compacted soils in terms of microstructural and hydraulic properties. Some tests are conducted on two different types of soil: silty sand and clay as fine soils and gravelous sand and alterite as granular soil. Some samples are mixed with $5 \%$ of cement and compacted at different levels (i.e., $85 \%, 95 \%, 100 \%$ and $105 \%$ of the maximum dry density, respectively, as achieved using the standard compaction method). The results of the mercury intrusion porosimetry (MIP) tests performed on these cement-treated soils reveal significant changes as regards macropores due to the combined effects of treatment and compaction. Consequently, a decrease in the permeability is clearly observed for all the tested soils when the degree of compaction increases. This decrease is significantly greater in fine soils, which are more sensitive to compaction effects than granular soils.
\end{abstract}

\section{Introduction}

Soil stabilization is a widespread technique used to improve workability and hydromechanical properties of soils. It consists in pulverizing natural soil, mixing it with a chemical additive like a hydraulic binder (hydrated lime, for instance) or chloride salts, and, finally, compacting the mixture obtained thoroughly. Lime is mainly used for the treatment of clayey soils and more specifically of expansive clays. Lime treatments being well-known and well-documented, the present study is focused on the stabilization with cement. Unlike lime, stabilization using cement can be applied to different types of soils and not only clayey soils. A better understanding of the interactions between the microstructure of cement-treated soils and their mechanical and hydraulic properties is discussed. The literature on cement-based soils is poor compared with lime-treated soils [1]. Hydraulic binders are known to govern change in treated soil microstructure. This change is amplified by the compaction process that takes place after treatment. The influence of the compaction rate on microstructural and hydraulic properties of compacted soils has been addressed in a

\footnotetext{
* Corresponding author: harifidy.ranaivomanana@univ-nantes.fr
} 
recent paper by Ranaivomanana et al. [2]. The authors highlight the decrease in macropore volume and the formation of micropores within clayey soils when the degree of compaction increases. The water permeability, therefore, also decreases by two to three orders of magnitude when the compaction rate increases. Consequently, our understanding of the combined effects of soil and compaction treatments on microstructural and hydraulic properties of treated soils still needs to be improved.

\section{Materials and methods}

\subsection{Soils tested and cement used}

Four types of soil are tested: Silty sand, gravelous sand, clay and alterite denoted by SS, GS, C and A, respectively. These different soils come from the northwest of France and have been sampled from the current extension project area for the high-speed railway line "LGV Bretagne-Pays de la Loire", which requires a geotechnical investigation of the soils of the site. Physical properties of soils are presented in reference [2]. The cement used for the treatment is a Portland limestone cement (CEM II/B-LL 32,5R CE CP2 NF) in compliance with the European Standards [3].

\subsection{Sample preparation and characterization of soils after compaction}

The soil water content is adjusted up to the desired compaction water content. The moistened soil is then blended in an airtight container with an ageing cycle of 48 hours for moisture homogenization. The cement content is expressed as dry weight of the soil. The homogenized soil is mixed with $5 \%$ of cement in a mechanical mixer during $5 \mathrm{~min}$. The compaction phase is performed according to the standard Proctor compaction procedure described in ASTM D698 [4]. The optimal density and water content are calculated from the compaction curves (Table 1) and used as reference values for the following preparation step.

Table 1. Physical properties of soils studied at OPN.

\begin{tabular}{|l|l|l|l|l|}
\hline Soil reference & SS & GS & C & A \\
\hline Water content $(\%)$ & 13.2 & 12.9 & 19.0 & 13.1 \\
\hline Dry density $\left(\mathrm{kN} / \mathrm{m}^{3}\right)$ & 19.3 & 19.6 & 17.5 & 19.5 \\
\hline
\end{tabular}

The compaction densities chosen for this study are 85, 95, 100, and 105\% of the SPO for the permeability measurements. It should be noted that for all the tests conducted here, the samples are prepared at the optimum water content. The tests are carried out using cylindrical samples $50 \mathrm{~mm}$ in diameter and $100 \mathrm{~mm}$ in height. Once compacted, the samples are prepared and immediately wrapped in a cellophane film. They are finally left at the laboratory ambient temperature $\left(20 \pm 1^{\circ} \mathrm{C}\right)$ for 28 days to ensure a sufficient hydration of the cement. Two characterization tests are performed on compacted soils: Mercury Intrusion Porosimetry (MIP) and water permeability measurements. MIP tests consist in injecting mercury into a dried and degassed material, and are carried out using a Micromeritics Autopore IV porosimeter, which can characterize pores between 0.06 and $350 \mu \mathrm{m}$ in diameter. In order to maintain the microstructure, the samples are dried by sublimation after a 24-hour freezing phase. The volume of mercury injected corresponds to the cumulative pore volume accessible to mercury. Assuming that the pores are cylindrical, 
the relationship between the accessible diameter $d_{c}$ of the pores and the mercury injection pressure $\mathrm{P}$ is given by Washburn's law as:

$$
P=-\frac{4 \sigma_{H g} \cos \theta}{d_{c}}
$$

$\sigma_{\mathrm{Hg}}$ is the mercury surface tension $\left(\sigma_{\mathrm{Hg}}=0.485 \mathrm{~N} / \mathrm{m}\right.$ at $\left.25^{\circ} \mathrm{C}\right)$ and $\theta$ the contact angle of the meniscus solid to mercury $\left(\theta=130^{\circ}>90^{\circ}\right.$ because mercury is a non-wetting fluid). Four permeability test series are carried out on compacted soils. Those tests are duplicated to ensure more representative results. Thus, two samples are tested for each chosen degree of compaction for a total of 32 permeability tests with an average duration of two months. The samples tested are prepared by static compaction using a hydraulic press with compaction force up to $50 \mathrm{kN}$. The permeability tests are carried out using flexible-wall permeameters.

\section{Results obtained on compacted soils}

\subsection{MIP tests results}

During the soil compaction phase, an association of particles and aggregations forms. Granular soils retain a lower tendency to form aggregates in contrast to fine soils, where they cluster into larger aggregates. When the aggregates form, the pore size distribution can be divided into micropores, i.e., intra-aggregate pores and macropores i.e., inter-aggregates pores. It has been previously observed by Ranaivomanana et al. [2] that the compaction process mainly affects the macropores. Moreover, compaction also affects pore interconnections by blocking the percolation paths and modifying the morphological parameters. The pore size distribution curves of the tested soils (natural and treated) are presented in Figure 1 and Figure 2.

Because of the formation of larger aggregates in addition to the hydrophilic performances of cement, the addition of cement to fine soils is characterized by the distribution of cement particles around the agglomerates without penetrating them [5]. Randomly, in certain zones, cement serves as a link between two adjoining agglomerates. Cement also contributes to fill the macropores whose number increases with the formation of hydration products. This suggests that during the compaction process of cement-treated soils, both size and volume changes in macropores can be assumed as the result of the addition of cement and of the compaction process. This assumption is confirmed by the MIP results displayed in Figure 1a to $1 \mathrm{~d}$ and Figure $2 \mathrm{a}$ to $2 \mathrm{~d}$. At $85 \%$ of the SPO values, which is the lower degree of compaction used in this study, both the volume and the size of the macropores are virtually the same (pore diameter around $60 \mu \mathrm{m}$ ) as those observed in natural materials (Figure 1a and Figure 1c). The influence of the treatment on the macropores, therefore, remains limited as long as sample compaction is low. An increase in the micropore volume in soils treated at $85 \%, 95 \%, 100 \%$ and $105 \%$ of the SPO values, however, is observed. These new micropores are associated to the voids between the cement grains and/or between the hydration products because their size and volume do not change with the compaction rate. Beyond $85 \%$ of the SPO value, a substantial decrease in macropore volume as well as size is observed on the treated soils when the degree of compaction increases (Figure 2a and Figure 2c). Although some similar trends are obtained on natural materials, the size and the volume of the macropores are smaller in cementtreated samples than in natural ones. At $105 \%$ of the SPO values, the macropores are unobservable in treated silty sand while they are visible in natural samples. Those 
observations corroborate the fact that the influence of the treatment is enhanced by the quality of the compaction and point to the possibility of optimizing treatments by using suitable degree of compaction. As mentioned previously, granular soils retain a low tendency to form aggregates.

Contrary to fine soils, the cement-based treatment of granular soils generates new aggregates resulting from the development of many strong bonds between the initial aggregates by cementation effect. Cementation obviously affects the macropores as shown by the MIP results obtained in gravelous sand (Figure $1 \mathrm{~b}$ and Figure $2 \mathrm{~b}$ ). For all the degrees of compaction examined in this research $(85 \%, 95 \%, 100 \%$ and $105 \%$ of the SPO values), a decrease in both size and volume of the macropores in the cement-treated gravelous sand is observed. However, the MIP results reveal another interesting aspect of the modification of the macropores. The changes appear to be independent of the degree of compaction. This interesting finding is a consequence of the cementation effect that stabilizes the microstructure by creating strong and durable bonds between the initial aggregates. Gravelous sand becomes, therefore, less sensitive to the density of compaction after treatment using cement (Figure 1b and Figure 2b). As in fine soils, an increase in the micropores volume associated with the voids between the cement grains and/or between the hydration products is also observed here. The MIP results obtained with cement-treated alterite (Figure 2d) reveal two apparently conflicting aspects: the formation of new macropores at $85 \%$ and $95 \%$ of the SPO values, respectively and the disappearance of these macropres at $100 \%$ and $105 \%$ of the SPO values, respectively, as in gravelous sand. This can be explained by the non-uniform homogenization of the tested samples during the preparation phase due to the destructuration of the alterite. A range of low porosity modes occurring between 0.05 and $1 \mu \mathrm{m}$ related to macropores is also observed in Figure $2 \mathrm{~d}$. These macropores appear to result from the destructuration of the alterite during the compaction phase despite the development of strong bonds between the initial aggregates, as with gravelous sand. This is confirmed by the fact that the newly formed macropores are independent of the compaction quality. Their size and volume, indeed, remain the same whatever the degree of compaction. This result satisfactorily agrees with that obtained using some natural materials, in which no variation of the macropore characteristics is noted when the degree of compaction increases (Figure 1d and Figure 2d).

\subsection{Water permeability results}

The permeability results are plotted on a semi-log scale as a function of the compaction rate (Figure 3). For both natural and treated fine soils, the permeability values (log. scale) linearly decrease almost identically (same slope) as the degree of compaction increases (Figure 3a and Figure 3c). These results are consistent with the MIP results and highlight the fact that the decrease in permeability values observed here is mainly the consequence of the macropore change caused by the compaction effects for natural materials and by both the compaction and treatment effects for treated materials. According to the MIP results, the macropore changes observed in the treated materials are greater than in natural ones as stated in the previous section. As a result, the fewer the macropores, the lower the permeability as shown in Figure $3 \mathrm{a}$ and Figure 3c. Notice that the difference between the permeability values of natural and treated materials is in the order of one to two orders of magnitude. As regards gravelous sand, permeability values also decrease linearly as the degree of compaction increases, but with a less marked slope for treated samples than for natural ones (Figure 3b). As mentioned above, the cementation effect stabilizes the microstructure of treated materials because of the development of strong and durable bonds between the initial aggregates. Therefore, the evolution of the permeability values obtained in treated gravelous sand is less sensitive to the density achieved in compaction than in 
natural sand, is not a surprise. However, according to the MIP results, the treated samples show greater variations in both the size and volume of the macropores than in the natural ones. This explains the difference between the permeability values of natural and treated materials of 2-6 orders of magnitude. For both the natural and the treated alterite, the permeability results also decrease linearly (Figure 3d). However, above $95 \%$ of the SPO, the permeability values obtained in the treated materials are 2-2.5 orders of magnitude greater than those measured in natural materials. This can be explained by the formation of new macropores resulting from the destructuration of the alterite during the compaction phase and despite the development of strong bonds between the initial aggregates. According to the MIP results, newly formed macropores are independent of the compaction rate, which may account for the fact that the permeability values obtained in the treated materials are less sensitive to the degree of compaction, as shown in Figure 3d.
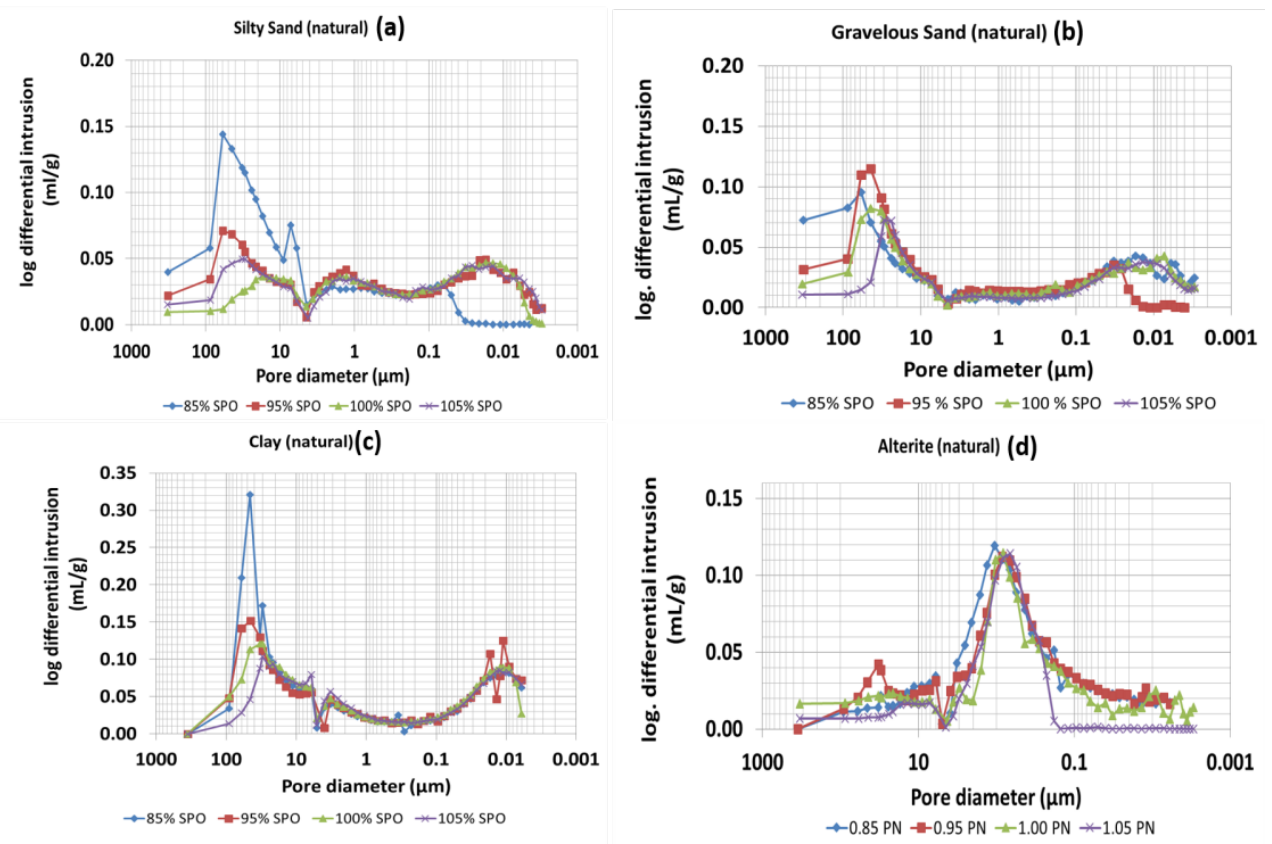

Fig. 1. Pore size distributions of natural soils for compaction rates in the present study. 

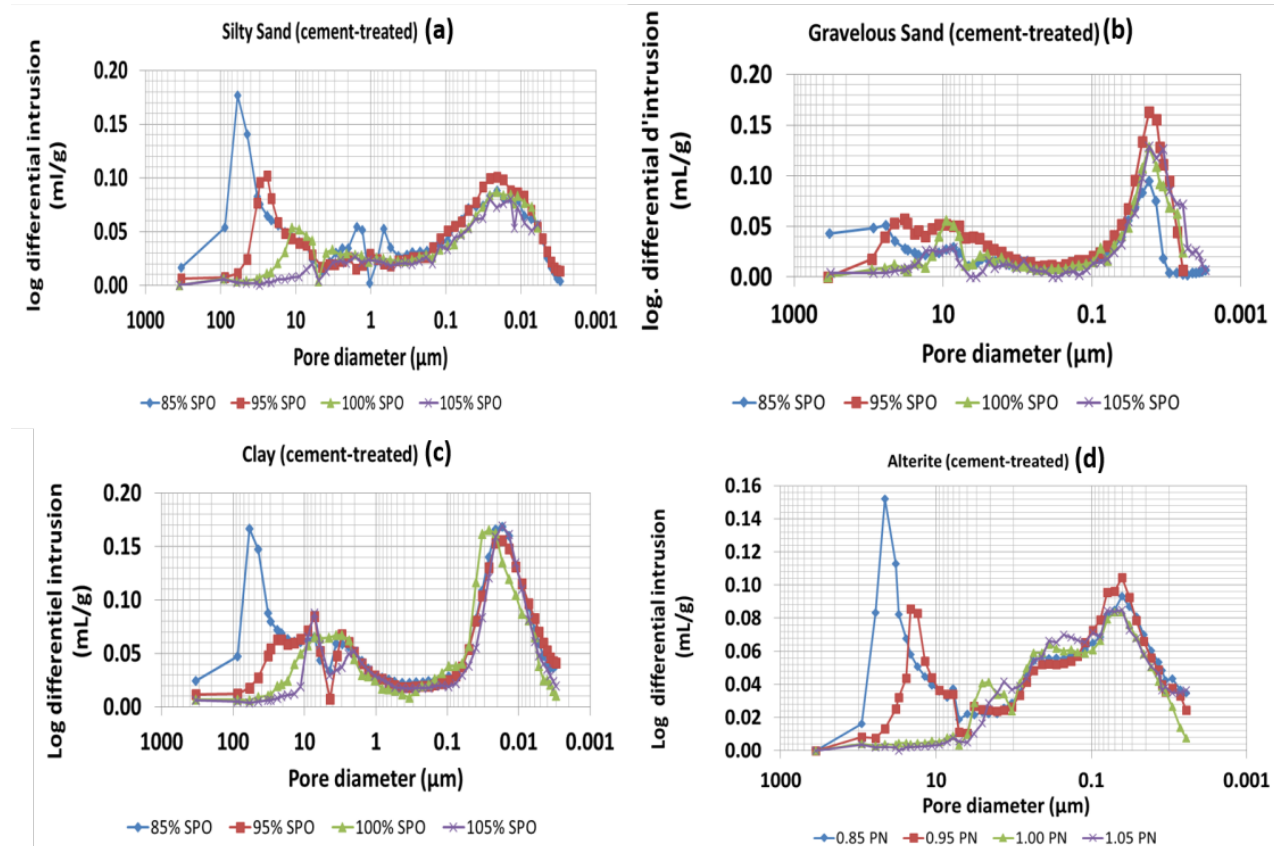

Fig. 2. Pore size distributions of treated soils for compaction rates in the present study.
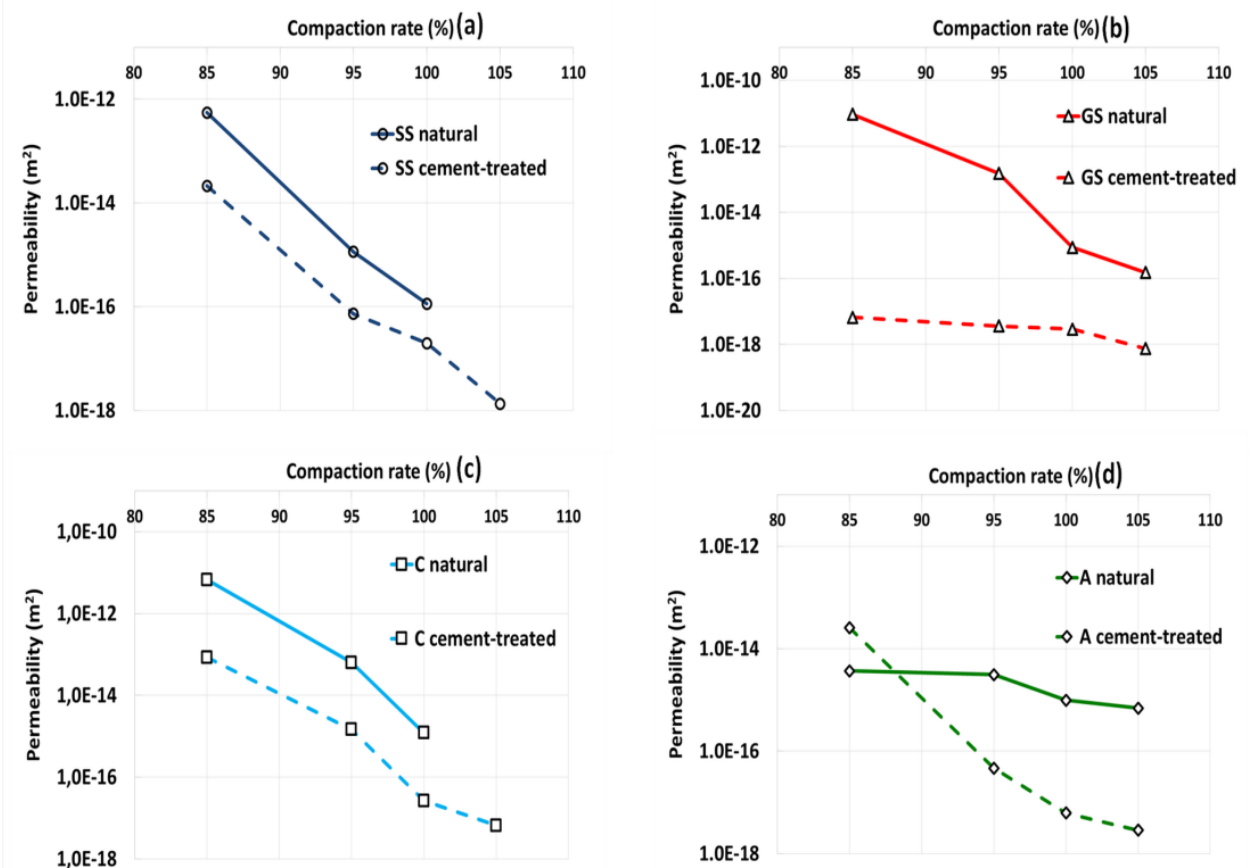

Fig. 3. Water permeability vs degree of compaction for natural and cement-treated soils. 


\section{Conclusion}

An experimental characterization of cement-treated compacted soils as regards the microstructural, hydraulic and mechanical properties has been conducted in this paper. Some tests have been conducted on two different fine soils (silty sand and clay) and on two granular soils (gravelous sand and alterite). The soils tested have been mixed with $5 \%$ of cement and compacted at $85 \%, 95 \%, 100 \%$ and $105 \%$ of the SPO values, respectively. The results of the mercury intrusion porosimetry (MIP) tests performed on cement-treated soils after compaction highlight the substantial decrease in both the size and volume of the macropores. This decrease is due to the combined effects of treatment and of compaction for the fine soils, and mainly to treatment as regards the granular soils. Such a process, indeed, initiates a cementation effect, which stabilizes the microstructure through the development of strong and durable bonds between the initial aggregates. It should be noted, however, that the formation of new macropores within cement-treated alterite is probably a result of its destructuring during compaction phase. The water permeability results are in accordance with the MIP results because liquid flows mainly takes place within the macropores. By plotting the water permeability evolution versus the degree of compaction with a semi-log scale, a linear decrease of this parameter is observed for all the tested soils as the degree of compaction increases. This decrease is particularly significant with fine soils, which are more sensitive to the effects of compaction than granular ones.

\section{References}

1. S. Bin S., L. Zhibin, C.Yi, Z. Xiaoping Z, J. Mater. Civ. Eng. 19 (2007)

2. H. Ranaivomanana, A. Razakamanantsoa, O. Amiri, Int. J. Geomech. 17(4), (2016)

3. EN 197-1 (2011)

4. ASTM D698 - 12e2 (2012)

5. K. Lemaire, D Deneele, S. Bonnet, M. Legret. Eng. Geol. 166 (2013) 
